\title{
HUMAN FUNCTIONAL ANATOMY OF VISUALLY GUIDED FINGER MOVEMENTS
}

\author{
by SCOTT T. GRAFTON, 1,2,3 JOHN C. MAZZIOTTA, 1,2,3 \\ ROGER P. WOODS ${ }^{2}$ and MICHAEL E. PHELPS 1.3 \\ (From the 'Division of Nuclear Medicine and Biophysics, Department of Radiology, the ${ }^{2}$ Department \\ of Neurology, University of California at Los Angeles School of Medicine and the ${ }^{3}$ Laboratory of \\ Nuclear Medicine, Department of Energy, USA)
}

\begin{abstract}
SUMMAR Y
The functional anatomy of visually guided movement was investigated in 18 normal subjects performing visuomotor tracking tasks during positron emission tomography imaging. Tracking a moving target with the index finger defined a network of focal responses of relative cerebral blood flow (relCBF) located in the primary motor cortex, dorsal parietal cortex, precuneate cortex, supplementary motor area (SMA) and ipsilateral anterior cerebellum relative to visual tracking alone. When the temporal complexity of the tracking task was altered by introducing a 'no go' contingency that allowed for greater time for movement preparation, there was a significant increase of relCBF in the SMA $(P<0.0001)$. When the spatial complexity was augmented by adding a secondary target that provided directional cues for the primary target, there were additional significant increases of relCBF in bilateral dorsal parietal cortex $(P<0.05)$ and precuneate cortex $(P<0.05)$. Although the cued 'no go' task was subjectively easier, relCBF responses were similar to the uncued 'no go' task in motor areas. Performing the tracking task with different body parts produced somatotopically distributed responses in only the motor cortex. The findings are concordant with clinical reports of patients with brain lesions and physiological evidence that identifies this distributed network for performing visually guided movement. The results provide direct human evidence in the normal brain that the supplementary motor area contributes in part to the sequencing of movements and the medial and dorsal parietal cortex participates in the integration of spatial attributes during selection of movements.
\end{abstract}

\section{INTRODUCTION}

Accurate, visually guided movement is a critical motor skill that is necessary for survival in most primate species. The simple act of reaching into extrapersonal space to touch a moving target requires a complex series of integrative steps that decode a vast amount of retinal information and culiminate in the recruitment of appropriate motor neurons for directed limb movement (Jeannerod and Prablanc, 1983). A rapidly growing literature has elucidated the sensory and motor extremes of this process; that is, visual analysis and motor control in both humans and non-human primates (Brooks, 1986; DeYoe and Van Essen, 1988). Concurrent processing streams direct visual information from striate cortex into visual association areas along multiple interconnected pathways. In nonhuman primate species, the connectivity maps of these parallel processes may be reduced to two paths necessary for the conversion of simple visual cues into associated useful attributes (DeYoe and Van Essen, 1988). The first, or 'what' pathway, is principally involved with object recognition and relies on visual cues of hue, binocular disparity

Correspondence to: Scott T. Grafton, Departments of Neurology and Radiology, University of Southem California, Clinical Sciences Center, Room 104, 2250 Alcazar Street, Los Angeles, CA 90033-4606, USA.

(C) Oxford University Press 1992 
and orientation selectivity (DeYoe and Van Essen, 1988). In the macaque species, for example, the path courses from the primary visual cortex to unimodal association area V4 into the inferotemporal cortex (Zeki, 1980; Maunsell and Van Essen, 1983; Ungerleider and Desimone, 1986). An analogous pathway has been proposed in humans, based on observations from brain lesions, functional imaging studies with positron emission tomography (PET) and electrophysiological experiments (Pearlman et al., 1979; Damasio, 1985; Lueck et al., 1989; Corbetta et al., 1990; Zeki et al., 1991). In humans the putative 'what' pathway extends in a cascade of processing centres from V 1 into inferior occipital areas such as the lingular gyrus and lateral occipital cortex and then into the middle temporal cortex (Corbetta et al., 1990).

The second, or 'where' pathway is critical for localization of objects in extrapersonal space and dependent on visual cues of hue, binocular disparity, orientation selectivity and movement selectivity (DeYoe and Van Essen, 1988). In the macaque species, information in this stream passes from striate cortex to inferior parietal cortex via area V3 and middle temporal cortex (Maunsell and Van Essen, 1983; Ungerleider and Desimone, 1986; Logothetis and Schall, 1989). An analogous pathway has been proposed in humans and courses from V1 into the inferior parietal lobe (Miezin et al., 1987, 1988; Corbetta et al., 1990).

At the opposite end of this neural network for visually guided movement, motor plans must be generated, executed and compared with ongoing movements. It has been suggested that the supplementary motor cortex initiates movements and possibly functions as an 'executor' for the sequencing of motor plans (Orgogozo and Larsen, 1979). The concept of 'executor' is based in part on the temporal differences in firing of supplementary motor area (SMA) neurons that are active prior to motor neurons (Freund, 1984). Premotor cortex activity has also been examined in great detail. One function is to interpret sensory attributes that represent triggers for the performance of previously learned patterned motor plans (Halsband and Freund, 1990). Prefrontal cortex has a more complicated role in motor control. For example, motor plans requiring temporal sequencing of movement in a correct order in response to sensory stimuli require a functioning prefrontal cortex (Goldman-Rakic, 1987; Fuster, 1989). Other areas are clearly functioning in tandem with the primary motor cortex. For example, ongoing 'feed forward' and 'feedback' adjustments for variations in force and position that keep motor plans within executable bounds are likely computed in lateral and parasagittal cerebellar zones (Thach, 1978; Stein, 1986; Leiner et al., 1987; Inhoff, 1989). The degree to which each of these areas acts 'upstream' rather than in parallel with the primary motor cortex has not been established

A major, long efferent association fibre track projects from dorsal parietal cortex into premotor cortex, prefrontal cortex and lateral cerebellum providing the necessary bridge between visual and motor association cortex (Fuster, 1989). Together, these cortical areas define a distributed set of processing areas required for the performance of visually guided movement. Somehow, the visual attributes in the first part of this network must be converted to a functional state necessary for action within the motor system. The goal of the current study was to investigate the functional anatomy of this network by using PET measures of relative cerebral blood flow (relCBF) as an estimator of local neuronal activity.

Given the multiplicity of pathways in this putative network, extending from visual 
cortex to motor neuron, we considered it unlikely that any single point in the brain would be responsible for integrating visual information into discrete motor plans. Rather, it is likely that this conversion occurred in both 'motor' and 'sensory' association areas, cerebellum and subcortical nuclei in a dynamic, parallel manner. From prior electrophysiological experiments in non-human primates, we were particularly interested in the role of the posterior parietal lobe in this conversion along the 'where' pathway (Mountcastle et al., 1975; Yin and Mountcastle, 1977; Jeannerod and Prablanc, 1983). We hypothesized that the activity of neuronal populations in this network would vary as a function of higher order contingencies demanded of our subjects while they performed a set of visually guided motor tasks. We developed a set of stimulation paradigms with different temporal and spatial complexities for comparison. We also varied the body part used to complete the visuomotor task, to examine the homuncular representation of the motor system and also to serve as an internal control. Theoretically, upstream or 'executor' motor areas and sensory association areas might not differ in the magnitude of their responses when different body parts were used during a tracking task.

We structured our control studies to account for three factors that could potentially confound our interpretation of local relCBF responses during the performance of visually guided movement. The first factor was the activation of cerebral cortex associated with smooth pursuit and saccadic visual tracking that might occur independently of any intended limb movement (Yin and Mountcastle, 1977; Miezin et al., 1987, 1988; Godoy et al., 1990; Morrow and Sharpe, 1990). Since we were interested in the organization of directed limb movement, this factor was controlled for by having the subjects perform the same tracking task with eyes alone. The second factor was the effect of attention (Spitzer et al., 1988). Evidence suggests that attention to extrapersonal space is executed as a dispersed, parallel distributed process with nodes located in the frontal eye fields, the inferior parietal lobe and the cingulate gyrus (Posner et al., 1988; Mesulam, 1990). Previous PET studies have demonstrated that heteromodal and 'upstream' unimodal visual association cortex responses are modulated by attentional mechanisms (Corbetta et al., 1990). We attempted to disassociate the relCBF responses associated with attention to extrapersonal space from responses secondary to the process of visuomotor planning, by instructing our subjects to perform an active control study. This consisted of visual tracking to a matched target rather than a more passive control state such as sensory deprivation. Finally, we used a target with a constant form, colour and intensity for both the stimulation and control studies to minimize potential activation along the 'what' pathway.

\section{METHODS}

\section{Imaging}

Images of relCBF were obtained in 18 normal subjects while they performed a series of visually guided motor tracking tasks. Arterial sampling was not performed so that subjects would have at least one untethered arm to perform the motor tasks. Each subject received six intravenous bolus injections of $50 \mathrm{mCi}$ of $\mathrm{H}_{2}{ }^{15} \mathrm{O}$ commensurate with dynamic PET imaging with the Siemens/CTI 831-08 tomograph (Siemens Corporation, Hoffman Estates, IL, USA). The device collects 15 contiguous planes, $6.75 \mathrm{~mm}$ thick, with an in-plane resolution of $6 \mathrm{~mm}$ full width half maximum (FWHM). The final images were reconstructed with a low resolution filter ( $13 \mathrm{~mm}$ FWHM) for the calculation of percent change images and a medium resolution filter $(9.5 \mathrm{~mm}$ FWHM) for anatomic localization (Figs 1, 2). Each emission image was corrected for 
attenuation using a transmission image of the subject collected in the same position with a Germanium-68 ring source. Head immobilization was achieved with a custom foam mold (Smithers Corporation, Akron, OH, USA).

Estimates of relCBF were based on a modified autoradiographic method (Herscovitch et al., 1983; Raichle et al., 1983). Five second frames were collected for 2 min beginning at the time of injection of $\mathrm{H}_{2}{ }^{15} \mathrm{O}$. The first frame showing the arrival of cerebral radioactivity was identified. From this time point the counts for the ensuing $70 \mathrm{~s}$ were summed to generate images of relCBF. Difference images demonstrated an optimal signal to noise ratio at approximately this scan duration (Mintun et al. , 1989; Grafton et al., 1990). Relative CBF images have a near linear relationship with absolute CBF and provide a reliable estimate of local CBF with a coefficient of variation of 2.54 for small sized $\left(<2 \mathrm{~cm}^{2}\right)$ regions (Fox et al., 1984; Mazziotta et al., 1985a). The average number of counts from each global relCBF image were determined and each image was rescaled on a pixel by pixel basis to a common mean of $50 \mathrm{ml} / 100 \mathrm{ml} / \mathrm{min}$. Effects of this normalization were assumed to cause relative underestimations for local increases in CBF and hence induce a conservative error. Since global changes of CBF are less than $5 \%$ when sensory deprivation is not used as a control state, the global effect on regional responses was assumed to be small (Cameron et al., 1990).

Eight subjects underwent magnetic resonance imaging (MRI) scanning with an inversion recovery protocol ( $\mathrm{TE}=30 \mathrm{~ms}, \mathrm{TI}=300 \mathrm{~ms}$ and $\mathrm{TR}=1275 \mathrm{~ms}$ ) that generated 30 contiguous planes of data with an interslice distance of $4.4 \mathrm{~mm}$ and in-plane resolution of $1 \mathrm{~mm}$ (Fonar Systems, 0.35 Tesla, Melville, NY, USA). The MRI scans were characterized as normal by an experienced neuroradiologist.

\section{Subjects}

All subjects were studied after giving informed consent in accordance with the UCLA Human Subject Protection Committee. Eighteen normal subjects ( 17 male, 1 female; mean age 23 yrs) were studied. All subjects were free of medications for at least $6 \mathrm{wks}$, with no history of nervous system disease, and were normal on detailed neurologic examination. Handedness was determined with a standardized questionnaire and the dominant side was used for performance of tasks unless otherwise specified (15 right-handed, 3 left-handed subjects) (Raczkowski and Kalat, 1974).

\section{Tasks}

Three different stimulation paradigms were presented to subjects from two distinct groups (Group A, $n=12$; Group $B, n=6$ ). Table 1 summarizes the organization of the tasks and comparisons of the groups. For the first stimulation paradigm, which we term 'continuous tracking', the subjects were presented with an identical randomly moving $0.5 \mathrm{~cm}$ target displayed on a 13 in colour video monitor coupled to a Macintosh Ilcx computer (Apple computers, Cupertino, CA, USA). The visual fields peripheral to the computer screen were shielded to eliminate potential visual distractions. The target, moving in a fixed window of $6 \times 8 \mathrm{~cm}$, had a velocity of $20.6 \mathrm{~cm} / \mathrm{s}$ and changed direction randomly (an average of 200 times per $\mathrm{min}$ ). There was an imperceptible pause of $80 \mathrm{~ms}$ for computer calculations prior to target displacement in a new direction. The scanning was performed in a dimly lit room where the only ambient sound was from a tomograph fan.

Twelve Group A subjects tracked the continuous tracking target with their dominant index finger. The subjects held an arm outstretched, with the index finger lightly touching the screen. They were instructed

TABLE I. SUMMARY OF STIMULI AND VISUOMOTOR TASKS

\section{Visual stimulus}

Group A Continuously moving target (CT)

Group B Intermittently moving target (IT) Intermittently moving target with directional cues (ITC)

\section{Comparison}

Index finger tracking-CT control

Tongue tracking-CT control

Toe tracking-CT control

Non-dominant index finger tracking-CT control

Index finger tracking-IT control

Index finger tracking with directional cues-IT control

Number of
subjects
12
5
4
2
6
6

Control $=$ active tracking of the visual stimulus with only eye movements. 
to keep the moving target covered as much as possible. The axis of rotation was about the first metacarpophalangeal joint. The hand was lightly braced against the video terminal for stability and the subjects were allowed to practise the tracking until only the first finger of their dominant hand slid gently over the target without any jumping movements.

Subjects practised the motor tasks for approximately $5 \mathrm{~min}$ prior to PET imaging. In a previously reported reproducibility study of continuous tracking with the dominant index finger, we found no evidence of a systematic change of the peak relCBF response with repeat measurement to suggest an effect of practice or habituation (Grafton et al., 1991). Each task was then performed for 2 min beginning with the bolus injection of $50 \mathrm{mCi}$ of $\mathrm{H}_{2}{ }^{15} \mathrm{O}$ and dynamic imaging. The subjects were monitored by visual inspection for any axial or appendicular movements other than the specified body part. They were also rated for their performance in following a target and rewarded monetarily if the target was covered greater than $50 \%$ of the time.

Two of the Group A subjects tracked the target twice with the dominant hand and twice with the nondominant hand.

Four of the Group A subjects followed the continuous tracking target with the great toe ipsilateral to their dominant hand. The leg was completely relaxed at the hip and knee and lay in extension. Flexion and extension of the great toe and rotatory movements at the ankle allowed for accurate tracking. Because the computer screen was closer to the subject's eyes than to the toe, the subjects did not have visual feedback from projection cues to confirm accurate spatial displacement of the toe in reference to the moving target on the computer screen.

Five of the Group A subjects tracked the continuous tracking target with their extended tongue. They were coached not to use their lips, face or limbs in concert with the tongue movements.

Each of these 12 subjects also performed matching control studies, during which the subjects were instructed to follow the movement of the same target with their eyes only.

The six subjects from Group B performed only index finger tracking, as opposed to other body parts, in response to two other stimulation paradigms (Table 1). In the first of these two paradigms, termed 'intermittent tracking', the same target as in the continuous tracking task was presented, and moving at the same speed of $20.6 \mathrm{~m} / \mathrm{s}$. The target changed direction less frequently, at 75 times per minute. Each target displacement ended with a $580 \mathrm{~ms}$ pause of fixed duration prior to the next displacement in a new direction. The subjects were instructed to keep the target covered with their dominant index finger. The task required finger tracking alternating with stationary target fixation and anticipation, and thus defined a 'no go' contingency.

In the other Group B stimulation paradigm, termed 'intermittent tracking with directional cue', the same primary target, 'no go' contingency and instructions were presented. In addition, a smaller $(0.25 \mathrm{~cm}$ diameter $)$ secondary target was presented. The secondary target would appear at the next intended site of displacement of the primary target $500 \mathrm{~ms}$ prior to the initiation of movement of the first target. Thus, the secondary target provided direction and distance cues for the accurate tracking of the primary target. Subjects were instructed not to jump ahead to the secondary target, but rather to keep the primary target covered at all times. The secondary target was also present in the intermittent tracking task to balance the number of targets presented between the two states; however, in the intermittent tracking task it lagged behind the primary target $(500 \mathrm{~ms})$ and provided no directional information.

Each Group B subject performed the intermittent tracking and intermittent tracking with directional cue tasks twice. Control images of eye movements alone were obtained for both the intermittent tracking and the intermittent tracking with directional cue tasks.

\section{Image analysis}

Percentage change of relCBF between two globally normalized images, where percent change $=$ [(Stimulus - Control)/Control] $\times 100$, were calculated within each subject on a pixel by pixel basis. Only increases in CBF were analysed for this report. Each percentage change image was analysed for misregistration in two ways. The first was to calculate the coefficient of variation of the distribution of all pixels in the brain on the percentage change image. A coefficient of variation greater than $30 \%$ was found to indicate misregistration. Also, the percentage change images were inspected for rims of activity along the cortical surface or as a halo over the dorsal portion of the brain that would occur with misregistration. Images from three subjects who would have been in the group of 18 subjects demonstrated these findings and they were excluded from this report. 
Image analysis was limited to brain regions hypothesized a priori, to be involved in the performance of visually guided movement. To define foci in these regions, peak sites of increased relCBF were directly identified on the percent change images of the continuous tracking and intermittent tracking with directional cue tasks in the bilateral primary motor cortex, dorsal parietal cortex, precuneate cortex, SMA and ipsilateral anterior superior cerebellum. All of the motor and cerebellar foci were statistically significant when tested with a Z-score analysis for detection of outliers in a difference image between one continuous tracking task and two control states for each Group A subject (Fox et al., 1988). Responses in parietal regions were near significance in Group A subjects and reached significance in the Group B subjects. The latter group had two studies per condition for comparison, and the associated reduction in variance increased the sensitivity to detect the parietal responses. Responses in premotor and postcentral gyrus cortex were not included because of the close adjacency to the primary motor cortex and partial volume effect. Although there may have been additional sites of significantly increased relCBF throughout the brain, the study design was blinded to them and they were not included in this analysis.

To verify the location of each focus noted above, the three-dimensional spatial coordinates for each were recorded and mapped onto the same subject's unsubtracted relCBF images (reconstructed with a high resolution filter of $9.5 \mathrm{~mm}$ FWHM for improved anatomical localization). The foci were also mapped onto MRI scans in the eight subjects with matching MRI sets (Pelizzari et al., 1989). This localization approach avoided the use of stereotactic translations of images from different subjects onto a generic atlas, a procedure that could potentially propagate errors in the identification of specific gyral anatomy (Fox et al., 1985a). To do the registration, contours at the skin surface obtained from the MRI and the PET transmission scan sets were aligned (Pelizzari et al., 1989). The PET percentage change images were then resliced to match the MRI set to allow for accurate anatomical localization of intrasubject cortical responses. An unsubtracted $\mathrm{H}_{2}{ }^{15} \mathrm{O}$ study from each subject was also resliced and compared with the MRI scan to verify the accuracy of the registration and alignment between the two study modalities.

The precentral gyrus and anterior superior cerebellum could be identified directly from the unsubtracted high resolution axial relCBF image or MRI (Fig. 1). To confirm localization of parasagittal foci, the unsubtracted relCBF image, MRI and percentage change images were resliced into $3 \mathrm{~cm}$ thick sagittal sections with the centre slice centred at the midline and, thus, including cortex from both hemispheres (Fig. 2). This was done using the 'Explorer' program and the Apple Macintosh computer (software developed

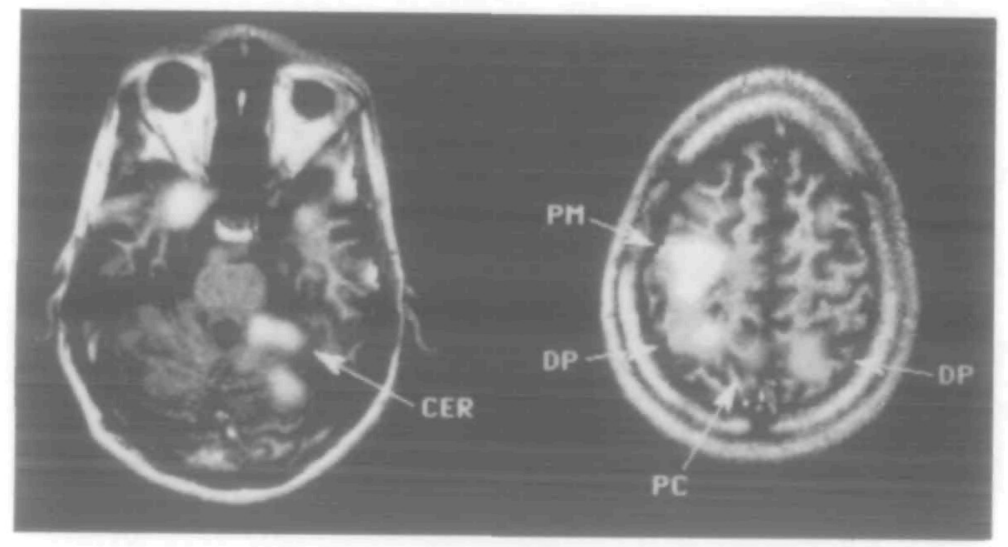

Frg. 1. Functional anatomy of continuous target tracking with the dominant (left) index finger. The PET relCBF images have been matched and registered with an MRI study from the same subject. All positive increases of relCBF (in white scale) are superimposed on axial MRI sections. A large focus is present in the right hemisphere spanning the precentral gyrus, the premotor area (PM) and extending into the postcentral gyrus. The peak site of response for this focus was in the precentral gyrus. Foci of activation are also present in the precuneate cortex (PC), and bilateral dorsal parietal (DP) cortex. Subtle increases of CBF are also visible in bilateral dorsolateral prefrontal cortex; however, this was not a consistant finding across subjects and was not included in the analysis. The inferior section demonstrates a response in the ipsilateral anterior cerbellum (CER). 


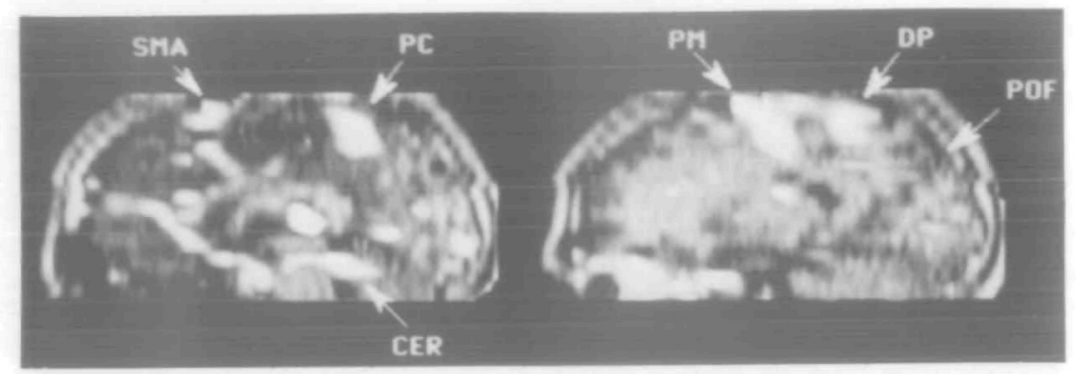

FIG. 2. Sagittal sections of relCBF and superimposed positive increases of CBF (in white scale) in a subject peforming the contınuous tracking task with the dominant index finger. Images have been resliced in a standardized manner to $3 \mathrm{~cm}$ thick sagittal planes. The midline section (left) demonstrates SMA and precuneate cortex (PC) foci antenor and posternor to the central sulcus, respectively, and an anterior cerebellar (CER) response inferior to the tentorium. The parasagittal section (right), passing through the dorsal parietal cortex, demonstrates dorsal parietal (DP) and superior motor cortex premotor area (PM) responses. The parieto-occipital fissure (POF) is visible as an additional anatomic reference. Foci are clearly detectable in other areas; however, they were not evaluated in this study.

by Osman Ratib, Gerold Porenta, and Bill Kuhle, UCLA Division of Nuclear Medicine and Biophysics, Los Angeles, CA, USA) (Ratib and Huang, 1989). The pre- and post-central gyri, calcarine cortex, cingulate sulcus and parieto-occipital fissure were identified on the midline sagittal section of each unsubtracted relCBF or MRI study (Fig. 2). These structures formed boundaries for the regionalization of precuneate, cuneate and posterior boundary of the supplementary motor cortex. The average distance from the medial central sulcus to the SMA response was $2 \pm 0.2 \mathrm{~cm}$ (Fig. 2).

We did not attempt to divide brain regions in parasagittal cortex into right and left sides because of the potential errors of quantification of closely placed foci on either side of the midline that would occur secondary to the partial volume effect in the low resolution percentage change images. Dorsal parietal cortex was defined on $3 \mathrm{~cm}$ thick sagittal sections located $3 \mathrm{~cm}$ lateral to the midline (Fig. 2).

After registration, alignment and reslicing of the PET studies, three-dimensional volume rendered images of the grey/white border of the MRI study were also created with Analyze program (Mayo Clinic, Rochester, MI, USA). The grey/white border was used for the MRI studies to allow for the visualization of deep sites of focal activation within sulci. Colour PET studies were then added at varying thresholds above a given percentage change in relCBF.

\section{Task comparisons}

Six of the subjects in Group A performed the index finger continuous tracking task twice and all of the Group B subjects performed the intermittent tracking and intermittent tracking with directional cue tasks twice. These paired studies were averaged together prior to calculation of percentage change images.

Table 1 summarizes the organization of the study comparisons. A direct comparison of Groups A and $B$ motor tasks could not be made since they were from different populations. Therefore, each task was analysed with respect to a matching control. The relCBF change in each site of the visuomotor network defined above could then be compared across groups and conditions. This strategy assumed that the control studies uniformly corrected for effects of visual tracking, attention and non-motor factors across groups and conditions. For each Group A subject, the control study was subtracted from the matching continuous tracking motor task and percentage change images were derived. Although the intermittent tracking without and with directional cue tasks were both performed by Group B, a direct comparison of these tasks was not made. Instead, relCBF changes with respect to the intermittent tracking control image were calculated to facilitate comparison with the Group A results.

\section{Response quantification}

Estimation of the magnitude of a relCBF response is confounded by the partial volume effect in reconstructed PET images. Response size and magnitude cannot be simultaneously determined. If structure size can be estimated from anatomic imaging such as MRI then a better estimate of the true magnitude of a 
response can be obtained. This strategy was used for estimating the magnitude of responses in subcortical structures, as described below. For measurements of cortical responses, where the boundary of structures is less certain on anatomical images, this strategy is still in development. Therefore, we used the maximum percentage change of relCBF in each cortical focus to quantify local responses. This measure, although given as a change in magnitude, also reflects, to an unknown degree, a change in response volume. In a previous study we determined that the coefficient of variation for this measure is approximately $9 \%$ in subjects performing the same task serially (Grafton et al., 1991). The variation in the site of the maximum response in the primary motor cortex, anterior cerebellum and SMA was also measured. Confidence intervals (95\%) defining spheres of radii $5.4 \mathrm{~mm}, 4.4 \mathrm{~mm}$ and $4.2 \mathrm{~mm}$ were defined for these three sites, respectively. That is, any two foci could be considered as significantly distinct if separated by approximately $5 \mathrm{~mm}$ in any direction. However, the magnitude of two adjacent foci could not be quantified if they were closer than the instrument resolving power (FWHM $=12 \mathrm{~mm}$ ).

Relative CBF responses in subcortical structures were measured with region of interest templates drawn on unsubtracted relCBF images or, when available, the matched and registered MRI scans over the right and left caudate, putamen and thalamus. Percentage changes in relCBF in these regions were then calculated. For brain structures spanning multiple image planes, the average relative increase in CBF, weighted by cross-sectional area in each plane, was calculated.

\section{Statistical analysis}

Between groups comparisons of the peak percentage change of relCBF responses were performed by analysis of variance (ANOVA). Inter-regional correlations were analysed by simple linear regression. A paired $t$ test was used to compare the peak responses of relCBF, measured at the same loci, between the intermittent tracking and intermittent tracking with directional cue tasks.

\section{RESULTS}

\section{Localization}

Reproducible focal responses of relCBF could be identified in all subjects. For those subjects with matched and registered PET and MRI, the three-dimensional localization of PET relCBF responses were displayed directly onto MRI and rendered in three dimensions (Fig. 3). This imaging approach allowed for the rapid visual screening of cortical blood flow responses in single subjects and provided an overall impression of the distribution of cortical sites contributing to cerebral operations linked to the neurobehavioural tasks being performed. All of the tasks were associated with distinct relCBF responses in both ipsilateral and contralateral primary motor cortex, SMA, dorsal parietal, precuneate cortex and ipsilateral anterior cerebellum. The aggregate of these sites formed a functional network active during visuomotor tracking. The effect of changes in somatotopic, temporal and spatial parameters on each site of this network could then be examined.

\section{Homunculus studies}

Focal increases of relCBF in the primary motor cortex followed the classic sequential somatotopic representation as defined by Penfield (Penfield and Boldrey, 1937). Bloodflow responses secondary to toe movements were close to the interhemispheric fissure, those of finger movements were approximately two-thirds of the distance from the lateral fissure to the interhemispheric fissure and those of tongue movements were close to the lateral fissure.

Quantitative measures of the magnitude of focal responses in different cortical sites as a function of the body part used to perform the continuous tracking task are summarized 


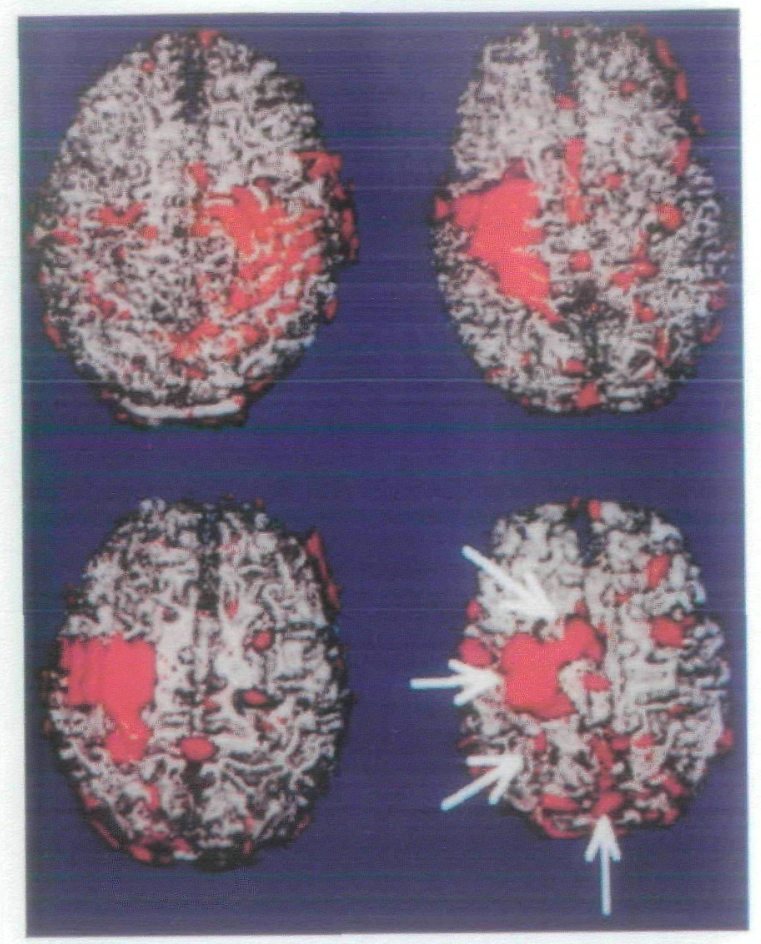

FfG. 3. The distribution of cortical responses associated with continuous finger tracking of the dominant index finger in three right-handed and one left-handed subjects (upper lefi). Three-dimensional surface rendered percentage change images of relCBF above a $10 \%$ increase (in red) have been mapped onto the same subject's registered and aligned MRI scan. The MRI images have been digitally edited so that the depicted surface is at the grey/white matter boundary. Frontal lobe is at the top and the subject's right hemisphere is to the right. The four arrows identify (clockwise, from bottom), the precuneate cortex, posterior panetal cortex, contralateral motor cortex/premotor area and contiguous dorsal parietal cortex, and SMA. This display technique allows for the rapid visual screening and interpretation of distributed blood flow responses associated with neurobehavioural tasks.

in Table 2. Although the subjects touched the screen with the index finger task and not the other tasks, there was no difference of the peak response in the contralateral primary motor cortex. Thus, the relative contribution of somatosensory input to the precentral cortex response was presumed to be minimal. Tongue movements were associated with symmetric motor cortex responses. Supplementary motor area responses did not vary as a function of body part; however, responses in the anterior cerebellum were significantly less during tongue movements. In the sensory association areas, there was no difference in the relCBF responses as a function of the body part used when the same continuous tracking stimulus was presented.

The hypothesis that discrete foci of increased relCBF were acting as a functionally connected unit could be examined by assessing the relative correlation of responses across subjects performing the index finger continuous tracking and eye tracking tasks. This definition of functional connectivity relies on a correlation of the magnitude of responses in spatially distinct sites, rather than a correlation of temporal responses. An analogous strategy has been used in several other recent PET investigations (Friston et al., 1990; 


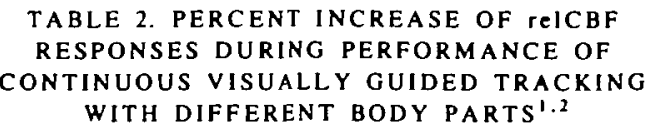

\begin{tabular}{|c|c|c|c|}
\hline \multirow[b]{2}{*}{ Conical sire } & \multicolumn{3}{|c|}{ Body pan } \\
\hline & $\begin{array}{l}\text { Index } \\
\text { finger }\end{array}$ & Tongue & Toe \\
\hline \multicolumn{4}{|l|}{ Motor contex } \\
\hline $\begin{array}{l}\text { Contralateral } \\
\text { Ipsilateral }\end{array}$ & $\begin{array}{l}35 \pm 9 \\
17 \pm 8\end{array}$ & $\begin{array}{l}34 \pm 7 \\
35 \pm 9 *\end{array}$ & $\begin{array}{c}40 \pm 13 \\
\text { n.m. }\end{array}$ \\
\hline \multicolumn{4}{|l|}{ SMA } \\
\hline $\begin{array}{c}\text { Bilateral } \\
\text { Anterior-cerebellu }\end{array}$ & \multicolumn{2}{|c|}{ Anterior-cerebellum } & n.m. \\
\hline $\begin{array}{l}\text { Contralateral } \\
\text { Ipsilateral }\end{array}$ & $\begin{array}{l}\text { n.m. } \\
32 \pm 9\end{array}$ & $19 \pm 8^{*}$ & $\begin{array}{c}\text { n.m. } \\
28 \pm 12\end{array}$ \\
\hline \multicolumn{4}{|c|}{ Dorsal parietal cortex } \\
\hline $\begin{array}{l}\text { Contralateral } \\
\text { Ipsilateral }\end{array}$ & $\begin{array}{l}15 \pm 5 \\
11 \pm 4\end{array}$ & $\begin{array}{r}11 \pm 5 \\
8 \pm 2\end{array}$ & $\begin{array}{r}10 \pm 4 \\
9 \pm 5\end{array}$ \\
\hline \multicolumn{4}{|l|}{ Precuneate cortex } \\
\hline Bılateral & $10 \pm 3$ & $9 \pm 2$ & $12 \pm 6$ \\
\hline
\end{tabular}

Chollet et al., 1991; Zeki et al., 1991). These interrelationships were examined by linear regression (Fig. 4). Because we were correlating difference images, the analysis examined interrelationships across both brain states and subjects. Significant correlations were present between the contralateral motor cortex and (1) ipsilateral motor cortex $\left(r^{2}=\right.$ $0.4, P<0.05)$ and (2) bilateral SMA $\left(r^{2}=0.48, P<0.05\right)$. In contrast, ipsilateral cerebellar relCBF responses were close in magnitude to contralateral primary motor cortex relCBF responses and there was no significant correlation between the two foci $\left(r^{2}=0.1, P>0.05\right)$, suggesting either a functional independence between these two areas or insufficient methodologic fidelity (due to excessive variance) to demonstrate a correlation. Similar significant relationships were also present for the responses during the tongue continuous tracking task. Thus, the interrelationship of responses in the SMA and ipsilateral motor cotex with the contralateral motor cortex responses were independent of the body part used.

\section{Response lateralization}

To further examine the possibility of hemispheric lateralization and effects of hand dominance, two subjects performed the continuous tracking task twice with their dominant hand and twice with their non-dominant hand. When using their non-dominant hand, the magnitude of responses in the contralateral (right) and ipsilateral (left) motor cortex were similar to responses of the contralateral (left) and ipsilateral (right) cortex with the dominant hand. In contrast, both subjects demonstrated SMA and cerebellar responses that were greater than the expected $95 \%$ confidence interval when the same task was performed with the non-dominant compared with dominant hand. Parietal responses during tracking with the non-dominant hand were symmetric homologues to those with 

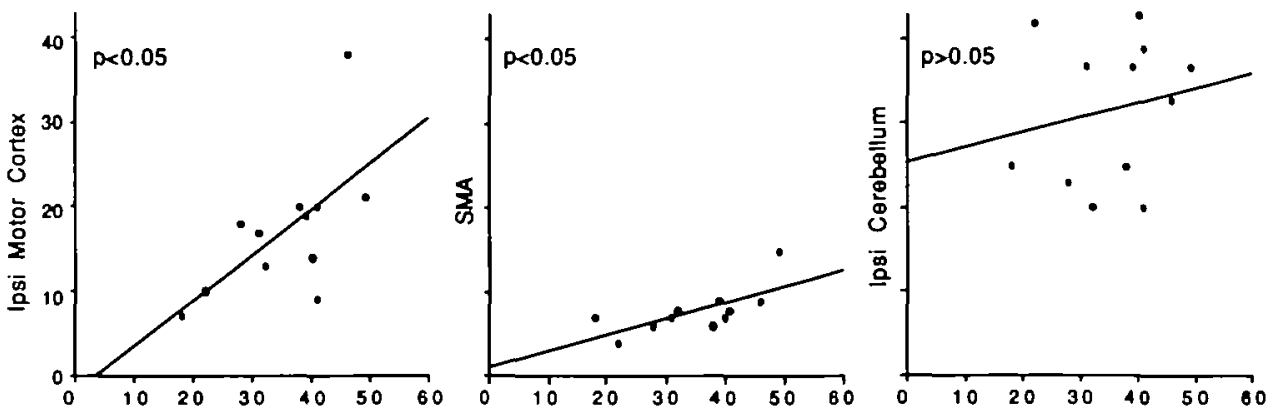

\section{CONTRALATERAL MOTOR CORTEX \\ (\% Increase of Relative CBF)}

Fig. 4. Scatterplot of relCBF responses in the contralateral primary motor cortex versus responses in the ipsilateral primary motor cortex $\left(r^{2}=0.4, P<0.05\right)$. SMA $\left(r^{2}=0.48, P<0.05\right)$ and ipsilateral anterior cerebellum $\left(r^{2}=0.1\right.$, $P>0.05$ ). The data are from the 12 subjects performing the continuous tracking task with their dominant hand. They demonstrate different degrees of covanance between different cortical motor areas, and suggest that the magnitude of response for some components of this network increase in parallel, as a functional unit.

the dominant hand. That is, greater relCBF responses were present in the hemisphere contralateral to the limb performing the task.

\section{Continuous versus intermittent tracking (dominant index finger)}

The effect of altering the contingencies required to perform each of the motor tasks with the dominant index finger was analysed by performing a group comparison across the three stimulation paradigms with ANOVA. The results are summarized in Table 3. The major operational difference between the intermittent tracking task and

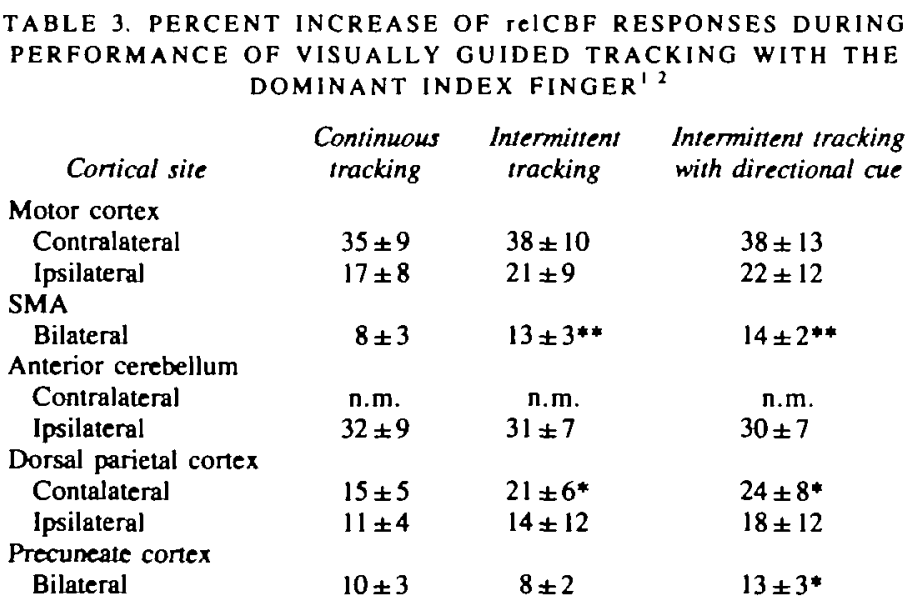

\footnotetext{
'Values are percentage increase of relCBF \pm standard deviation, measured at the peak site of response in each cortical site. ${ }^{2}$ Between group comparisons by ANOVA, $* P<0.05 ; * * P<0.0001$. n.m. = not measured, see Methods.
} 
the continuous tracking task was the introduction of a 'no go' contingency. The addition of this temporally predictable attribute was associated with a significant increase of relCBF in the SMA $\left(\mathrm{F}_{2,23}=14.0, P<0.0001\right)$. Despite the decrease in the number of directional changes per minute with the introduction of a 'no go' contingency compared with continuous tracking, there were no differences in the magnitude of relCBF responses in contralateral motor cortex $\left(\mathrm{F}_{2,23}=0.14, P>0.05\right)$, ipsilateral motor cortex $\left(\mathrm{F}_{2,23}=0.67, P>0.05\right)$ or cerebellum $\left(\mathrm{F}_{2,23}=0.17, P>0.05\right)$. No significant differences were noted between the continuous tracking and intermittent tracking tasks in either dorsal parietal or precuneate foci. Therefore, the addition of a 'no go' contingency was reflected most dramatically by an increased response of the SMA.

\section{Intermittent tracking with directional cues}

Performance of the intermittent tracking task with directional cues added both vectoral and distance information; that is, visuospatial attributes, to the 'no go' intermittent tracking paradigm. With this task there were no significant between group differences of relCBF in any of the motor areas examined (Table 3 ). In contrast, there were significant increases of relCBF in contralateral dorsal parietal cortex $\left(\mathrm{F}_{2.23}=4.77, P<0.02\right)$ relative to the continuous tracking task, and in the precuneate cortex $\left(\mathrm{F}_{2.23}=3.66, P<0.05\right)$ relative to both the continuous tracking and intermittent tracking tasks.

Because the intermittent tracking and intermittent tracking with directional cue tasks were performed by a single group of subjects, a pair-wise comparison could be made to detect differences in foci related to these two tasks. The increased demand of visuospatial processing during performance of the intermittent tracking with directional cue task was associated with significant increases of relCBF in the contralateral dorsal parietal cortex $(P<0.02)$, ipsilateral dorsal parietal cortex $(P<0.05)$ and precuneate cortex $(P<0.05)$ relative to the intermittent tracking task (Fig. 5). The parietal response was greater on the contralateral (left) side in all six subjects.

After completion of the study, the subjects reported that the intermittent tracking task was subjectively easier to complete when the directional cue was provided. Despite this reported decrease in task demand on the subjects, the responses in motor cortex, SMA and cerebellum were similar in the two tasks (Fig. 6). Thus, the predominant effect of altering the complexity of the interpretation of visuospatial information was an increase of relCBF in bilateral dorsal parietal and precuneate cortex.

\section{Subcortical responses}

Quantitative region-of-interest analysis of the right and left putamen, caudate, globus pallidus and thalamus revealed no significant between group differences of relCBF associated with any of the tracking tasks. Regional responses ranged from $0 \%$ to $2 \%$ of increased relCBF, values that were not significantly greater than measures of image noise derived from control minus control comparisons. In addition, no asymmetries of relCBF were noted in subcortical structures. Correlation analysis demonstrated no significant linear regression fits between any subcortical and cortical structures.

\section{DISCUSSION}

Using a set of related tracking tasks, we examined a cerebral network that is active during the performance of a set of visually guided movements relative to visual tracking 

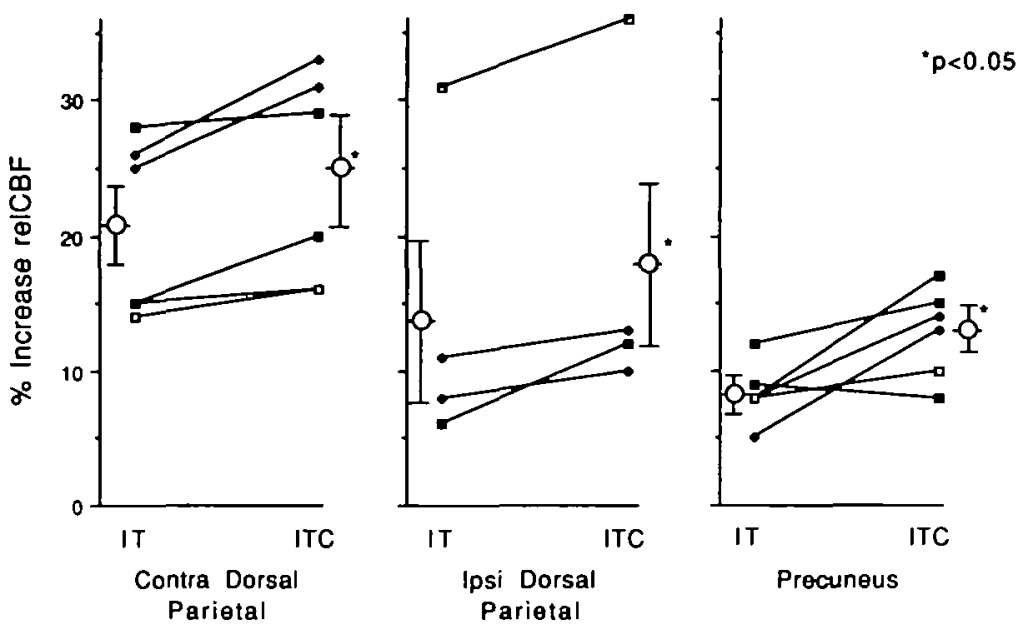

FIG. 5. Scatterplot of focal relCBF responses in contralateral dorsal parietal cortex, ipsilateral dorsal parietal cortex and precuneate cortex for the six subjects performing the intermittent tracking (IT) and intermuttent tracking with directional cue (ITC) tasks. Foci in all three areas demonstrated a significant increase of relCBF by paired two-tailed $t$ test when the visuospatial complexity of the task was augmented by the presentation of additional directional and distance information useful for goal-directed index finger tracking.
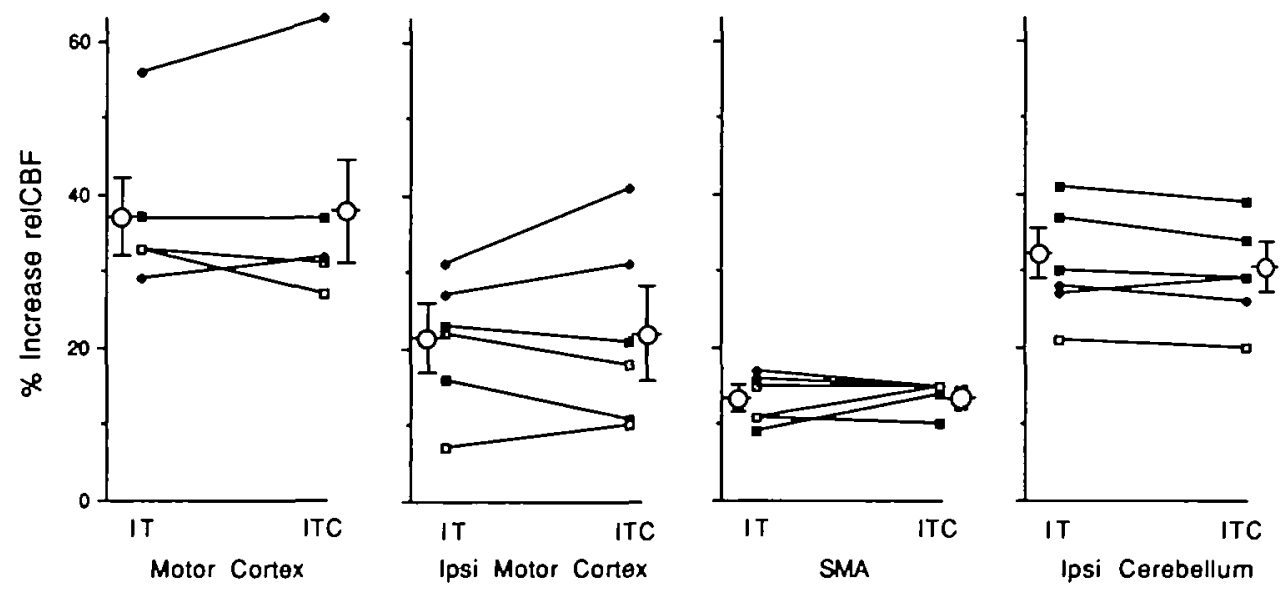

Fig. 6. Scatterplot of focal relCBF responses in contralateral motor cortex, ipsilateral motor contex, SMA and ipsilateral anterior cerebellum for the six subjects performing the intermittent tracking (IT) and intermittent tracking with directional cue (ITC) tasks. Foci in all four areas demonstrated no significant change of relCBF by paired two-tailed t test even though the tasks were subjectively easier with the addition of direction and distance cues in the ITC task.

alone. The network is widely distributed, involving sensory association cortex, cerebellum and multiple motor areas. The common functional attributes measured across conditions that induce responses in this network include movement selection, sequencing and execution. Common functional attributes controlled for across conditions would include visual tracking, attention and non-motoric effects of the scanning environment. 
We investigated the functional properties of each site of the cortical network by altering the somatotopic, temporal or spatial complexity in the neurobehavioural tasks. Our neurobehavioural paradigm design could not separate purely motor from sensory components to identify a discrete site of the brain where visual information was transformed into signals for motor control. That is, all four conditions measured effects of visual integration, motor selection and sequencing to different degrees. The findings show that different cortical domains are more or less active with various aspects of this visuomotor interaction. Since our analysis was performed on a limited set of brain areas, we cannot exclude the possibility that additional cortical sites are also involved in visuomotor processing. The properties of each of the brain regions that were investigated will be discussed in light of previously reported functional attributes suggested by the deficits associated with acquired lesions and neuronal responses determined by neurophysiological experiments and PET studies of these same areas.

\section{Parietal lobe}

The most interesting finding in this study was the enhanced activation of bilateral superior parietal and precuneate cortex during cued visually guided movement. Parietal responses were present for all the visuomotor tasks, irrespective of the limb used or whether there was a somatosensory feedback or not. They were significantly greater during intermittent tracking than continuous tracking. Of note, parietal responses were maximal when a directional cue was also introduced. This task and matching control were designed so that the subject would have to select and integrate useful visual information into a pre-existing, goal directed motor plan. Previous PET studies have demonstrated activation of the dorsal parietal region during visually directed movement. In early studies, effects of attention, eye movements, visual scanning and motor performance were not controlled for and thus interpretation of the specific contribution of dorsal parietal cortex to visuomotor processing could not be deduced (Roland, 1984). A recent PET study of the selection of movement in which these potentially confounding variables were carefully controlled for, has also demonstrated robust responses of CBF in the superior parietal cortex (Deiber et al., 1991). Responses in this area were present whether the task was driven by internal or external (auditory) cues compared with fixed movements, suggesting a critical role of this area for movement selection, rather than movement execution. Our results using visual cues demonstrate that this site, along with the precuneate cortex, is critical for movement selection based on the integration of visual information as a step in generating an executable visually guided motor plan. The combined PET results suggest that the responses in bilateral dorsal parietal cortices during selection of movement are in part modality-independent, since they occur with both visual and auditory external cues as well as internal cues. Further studies may define whether there are modality specific subregions within the superior parietal cortex.

Localization of PET relCBF responses to bilateral dorsal parietal and precuneate cortex during visually guided movement are concordant with the clinical state known as 'optic ataxia'. This sign, manifest as an inability to point or reach accurately at a target under visual guidance, was first decribed by Balint in a patient with bilateral occipital-parietal lobe lesions (Balint, 1909). The patient also had defects of impaired visual scanning (ocular apraxia) and visual disorientation (simultagnosia) and represents the hallmark case for Balint's syndrome (Balint, 1909). Since that report, it has been repeatedly 
demonstrated that optic ataxia can occur in isolation with either unilateral or bilateral posterior parietal lesions (Garcin et al., 1967; Rondot and de Recondo, 1974; Boller et al., 1975; Tzavaras and Masure, 1976; Rondot et al., 1977; Levine et al., 1978; Damasio and Benton, 1979; Auerbach and Alexander, 1981; Denes et al., 1982; Ferro et al., 1983; Ferro, 1984; Perenin and Vighetto, 1988). The findings of optic ataxia are distinct. It is a visuomotor disorder without visual field loss, inattention, neglect or visual space misperceptions. It is modality specific; patients preserve accuracy in pointing to sounds or to parts of the self by using audio or somatosensory cues for spatial orientation. Elementary motor function is unaltered; however, in a fraction of cases there may be hypokinesia, slight weakness, abnormal resting arm posture or slowing of alternating finger movements. The visuomotor deficit is seen in both distal and proximal limb components, manifest as errors in reaching, hand orientation and individual finger movements.

In the most extensive study to date, Perinen and Vighetto compared the location of abnormalities in eight patients with optic ataxia (Perenin and Vighetto, 1988). The lesion's most common location was in the contralateral interparietal sulcus extending into the superior parietal lobule and the precuneus (Fig. 7). The location is in excellent agreement with the site of superior parietal responses detected in our PET visually guided finger-

A
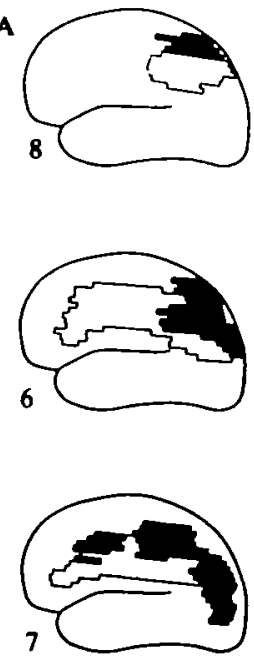
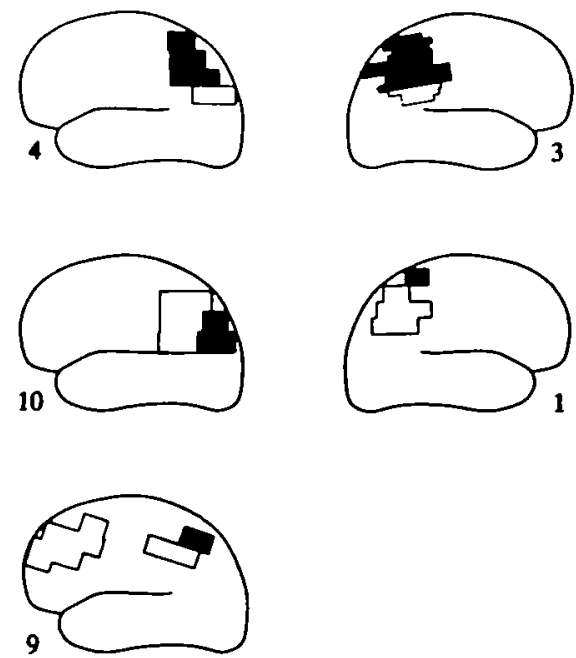
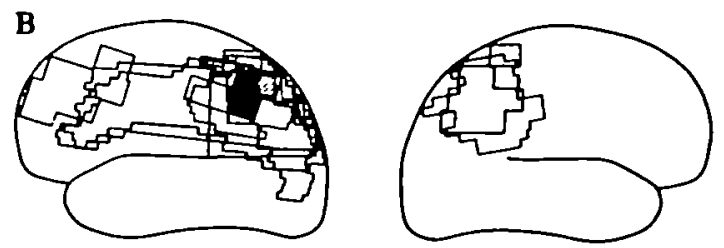

FIG. 7. Reconstruction of the CT location of parietal lesions in eight patients with optic ataxia. The common locus is in the region of the interparietal sulcus, superior parietal lobule and precuneus, similar to the responses obtained with PET during visually guided movement (adapted from Perenin and Vighetto, 1988). A, individuals; B, group composite. 
tracking tasks, demonstrating a close correlation between PET functional responses and clinical deficits from lesion studies.

Functional comparisons of our parietal lobe PET relCBF responses with electrophysiological studies of single unit recordings in non-human primate species should be made with some caution. The PET relCBF measures of cerebral 'activation' measure large neuronal populations with functional properties that are more general than those derived from single neuron studies. Ideally the attributes of single neurons should be concordant with responses associated with PET studies using similar neurobehavioural paradigms. Differences in the cytoarchitectonic organization of the dorsal parietal cortex between species must also be accounted for. For example, the human parietal lobe has considerably greater mass in Brodmann's areas 5 and 7 as well as additional gyri not present in other primate species, such as the angular and supramarginal gyri. Despite these complexities, important similarities exist between species.

Parietal lobe neurons of the macaque species have been parcelled into two domains corresponding to the superior (Brodmann's area 5) and inferior (Brodmann's area 7) parietal lobules. Neurons in the superior parietal lobule are active with passive joint rotation, deep tissue sensation and hand manipulation, amongst others (Mountcastle et al., 1975). In humans, the dorsal parietal cortex adjacent to the postcentral gyrus (Brodmann's area 5) is active during somatosensory association tasks. Lesions at this site typically cause astereognosis and agraphaesthesia (Ginsberg et al., 1987). This site is anterior to the superior parietal responses associated with our PET study, suggesting a functional disassociation of visual and somatosensory processing in the dorsal parietal lobe.

Unlike Brodmann's area 5, neurons of the inferior parietal cortex, in non-human primates, coresponding to Brodmann's area 7, are active during visual fixation, projection and hand manipulation, visual tracking, and recognition of visual space, amongst others (Mountcastle et al., 1975). Lesions of this area that extend posteriorly to the parietooccipital junction cause defects in exploration of extrapersonal space characterized by visual inattention and neglect, with or without visual field defects (Haaxma and Kuypers, 1974).

Visuomotor experiments of the superior and inferior parietal cortex (Brodmann's area 7) in humans compared with other primate species are best interpreted in the context of the functional anatomy of visual attention and goal-directed behaviour. Mesulam has recently reviewed the important role of the inferior parietal lobe (von Economo's area PG) as a node for directing attention to multimodal information travelling in parallel distributed processes (von Economo, 1929; Mesulam, 1990). The well-known deficits of hemineglect, simultagnosia and impaired visual scanning are all associated with lesions in this area, particularly when located in the right hemisphere. The PET studies in humans have also demonstrated activation of the inferior parietal lobe during attention to object velocity (Corbetta et al., 1990). Our results support the hypothesis that the human posterior parietal lobe (Brodmann's area 7) may be partitioned into inferior and superior functional units corresponding approximately to the inferior parietal lobule and superior parietal and precuneate cortex. The former area is involved in directed visual attention and is an early 'node' (in the temporal sense) of the 'where' pathway for visual processing, critical for the recognition of movement and velocity. The superior parietal and precuneate cortex are necessary for integrating visual cues into movement selection, independent 
of the body part used to perform the task. Whether an analogous functional distinction is also present in other primates remains to be determined.

Additional evidence from lesion studies would suggest a dichotomous flow of visual information from inferior parietal and parieto-occipital cortex to the superior parietal lobe. Although focal lesions can cause optic ataxia without defects in visual scanning, the converse is not true. When other defects such as Gerstmann's syndrome, ideomotor apraxia, optic apraxia or neglect were also present with optic ataxia, the lesion typically extended to the inferior parietal lobe or parieto-occipital junction (Heilman et al., 1986; Pierrot-Deseilligny et al., 1986; Perenin and Vighetto, 1988; Trillet et al., 1989). The findings suggest a dissociation of function necessary for the computation of visual information for the performance of visuomotor tasks. Visual attention must first be directed to an object before the object can be interpreted as a target that has value in the context of goal-directed behaviour (Jeannerod and Prablanc, 1983). Once this interpretation is made, a goal-oriented motor plan is generated. Both steps are likely gated by internal drives arising from limbic, cingulate and frontal cortical domains (Mesulam, 1981; Posner et al., 1988).

Deficits associated with inferior parietal lesions in humans typically demonstrate functional lateralization with neglect more commonly associated with right hemispheric lesions (Heilman and Van Den Abell, 1980; Mesulam, 1981). We could not detect a similar pattern of hemispheric lateralization in the relCBF responses of the superior parietal cortex. Although the number of subjects performing the continuous tracking task with the dominant and then non-dominant hand was small, we found that posterior parietal responses were always greater in the contralateral hemisphere for both the dominant and non-dominant hand. The findings suggest a hand effect without hemispheric lateralization.

Since we used full visual field stimulation, field effects could not be examined directly. Most patients with optic ataxia have a unilateral injury to the dorsal parietal lobe and are impaired in reaching with either hand for objects located in the visual field contralateral to the parietal lesion, consistent with a visual field organization of this region (Perenin and Vighetto, 1988). In some, however, there is impairment of a single hand in one hemifield, suggesting a hand effect (Tzavaras and Masure, 1976; Auerbach and Alexander, 1981). We would propose that bilateral dorsoparietal cortex is comprised of a mixture of both hand and field sensitive neurons. This would be the cortical level at which extrapersonal hemispheric spatial information is transformed into an intrapersonal somatotopic representation. Long association fibres project from the dorsal parietal cortex into premotor and prefrontal cortex, providing the critical link from sensory to motor association areas from which motor action can be orchestrated.

\section{Supplementary motor area}

A role for the SMA in the sequencing of movement has long been postulated, based on observations from lesion studies, electrophysiological recordings, blood flow imaging and direct cortical stimulation (Ingvar and Philipson, 1977; Lassen et al., 1977; Lauritzen et al., 1981; Freund, 1984). Lesions within this dorsomedial site are associated with a severe reduction in spontaneous motor activity, arrest of propositional speech, impaired bimanual coordination, the development of mirror writing or movements and impairment of memory guided saccadic eye movements (Brinkman, 1981; Laplane et al., 1981; 
Goldberg, 1985; Chan and Ross, 1988; Gaymard et al., 1990). The concept that the SMA operates as a 'supramotor' centre for the sequencing and initiation of movement is supported by the loss of spontaneous movement and speech after bilateral SMA injury (without paralysis), the presence of early negative potentials on scalp recordings emanating from this area (Bereitschaftspotential) and CBF imaging studies that have shown an increase of flow during both motor ideation without movement and with the performance of complex finger movements (Ingvar and Philipson, 1977; Orgogozo and Larsen, 1979; Roland et al., 1980; Deecke, 1987). Our results are concordant with the concept that the SMA acts as a movement sequencer, independent of body part used to perform the task. We found a significant increase of relCBF in this region when the tracking task changed from a continuous to an intermittent 'no go' paradigm. In the latter case the subject is allotted greater time for movement preparation. Another recent PET result has demonstrated an analogous finding (Deiber et al., 1991). A greater response was noted in the SMA when subjects were allowed to prepare a movement before an internally driven cue rather than an external cue. The two studies used different types of external stimuli, suggesting this function of the SMA is not modality specific. Our data would suggest that the SMA may not be involved with the integration of visuomotor targets into a motor plan. When a directional and distance cue was added to the 'no go' task, we detected no further augmentation of relCBF in this area. The SMA may be a sequencer of motor plans that are molded into more precise movements by other cortical areas utilizing visual, somatosensory, spinocerebellar and vestibular feedback.

Supplementary motor area responses may also reflect the difficulty of a motor task. We found a significant correlation between SMA and motor cortex responses across all subjects, suggesting they respond as a functionally connected unit. In addition, we found that SMA responses were significantly greater when subjects performed the same tracking task with the non-dominant hand, even though motor cortex responses were similar to the dominant hand. The non-dominant motor cortex may require a greater modulation by the SMA to perform an equivalent task than the dominant cortex. Characterization of regional interrelationships such as these will be critical for the interpretation of findings in patients with functional recovery after cerebral injury or developmental plasticity (Brion et al., 1989; Calford and Tweedale, 1990; Chollet et al., 1991).

\section{Cerebellum}

Previous mapping studies with PET have demonstrated increased CBF in the human cerebellum during patterned finger movements and with maintenance of hand posture (Fox et al., 1985b; Colebatch et al., 1990, 1991). When task execution is controlled for, responses are no longer significant (Deiber et al., 1991). In our study, no differences were noted as the spatial or temporal complexity was altered. The common denominator of the PET anterior cerebellar responses, therefore, has been execution of motor tasks driven by either visual, auditory or internally programmed cues. The response in our study varied as a function of the body part used, with a diminished response during tongue (axial) compared with toe or finger (appendicular) movements, suggesting functional specialization for limb rather than axial movements. It has been proposed that this cortical region of the cerebellum serves as a 'comparator' concerned with the detailed execution of movement (Thach, 1968, 1978; Lundberg, 1971; Strick, 1983; 
Stein, 1986; Leiner et al., 1987; Lisberger, 1988; Inhoff et al., 1989). The major afferents in this area are from the prefrontal and premotor cortex via cortico-ponto-cerebellar mossy fibres and the extrinsic spinocerebellar afferents providing proprioceptive information from the periphery (Vachananda, 1959; Tsukahara $e t$ al., 1968). Desired limb position, commanded by motor cortical areas are compared with actual limb position, signalled by the proprioceptive afferents. Disruption of the outflow from this area by cooling of the interpositus nucleus causes a delayed and insufficient compensation in response to a mechanical torque pulse, leading to limb oscillation (Stein, 1986).

\section{Precentral cortex}

The magnitude of relCBF responses remained constant across somatotopic, temporal and spatial contingencies, suggesting a relative stability in the execution of the different motor plans. The robust response in the primary motor cortex allows for non-invasive mapping of the primary motor cortex in individual subjects. This may be applied clinically to patients with a number of cerebral disorders including arteriovenous malformations, neoplasms and epilepsy. The combination of PET and MRI can be used as a preoperative localization technique for optimizing resection boundaries.

\section{Subcortical sites}

No significant increases in regional relCBF were demonstrated in basal ganglia nuclei for any of the tasks. The absence of these basal ganglia responses in our study may be a function of the random visuomotor task we used. Our task was unpatterned and used an active control state with eye movements. Previous authors have demonstrated striatal and thalamic responses in subjects performing a patterned task requiring digit tapping in a complex sequence compared with a control state of sensory deprivation (Roland et al., 1982; Mazziotta et al., 1985b). Subcortical responses have also been noted in patients after recovery from stroke who perform similar patterned digit movements (Chollet et al., 1991).

\section{Methodological considerations}

An implicit assumption of our report, among others, has been that a linear relationship between CBF and neuronal activity is present throughout heteromodal association cortex, motor areas and subcortical nuclei. It remains to be determined how cortical neurons control local CBF as a first step towards confirming this linear relationship throughout the neocortex. Comparative studies that combine electrophysiological and PET imaging methods in non-human primates or humans undergoing cortical mapping are needed to characterize the spatial and temporal features that couple flow and neuronal activity.

Our results demonstrate that functional attributes may be studied in a widely dispersed cortical network by minor alterations of a neurobehavioural paradigm. The PET approach allows for the simultaneous examination of a large-scale network, and provides a map that localizes the optimal sites for more detailed analysis with electrophysiological or biochemical techiques.

\section{ACKNOWLEDGEMENTS}

The authors wish to thank D. K. Mahoney, O. Ratib, G. Porenta and W. Kuhle for software development, and Lee Griswold for preparation of illustrations. This work was supported in part by DOE cooperative agreement No. DE-FC03-87ER60615 and NIMH grant ROI-MH-37916. 


\section{REFERENCES}

Aueranch SH, Alexander MP (1981) Pure agraphia and unilateral optic ataxia associated with a left superior parietal lobule lesion. Joumal of Neurology, Neurosurgery, and Psychiatry, 44, 430-432.

BALINT R (1909) Seelenlähmung des 'Schauens', optische Ataxie, räumliche Störung der Aufmerksamkeit. Monatschrift für Psychiatrie und Neurologie, 25, 51-81.

Boller F, Cole M, Kim Y, Mack JL, Patawaran C (1975) Optic ataxia: clinical-radiological cortelations with the EMIscan. Joumal of Neurology, Neurosurgery, and Psychiatry, 38, 954-958.

BRINKMAN C (1981) Lesions in supplementary motor area interfere with a monkey's performance of a bimanual coordination task. Neuroscience Letters, 27, 267-270.

Brion J-P, Demeurisse G, CAPON A (1989) Evidence of cortical reorganization in hemiparetic patients. Stroke, 20, 1079-1084.

Brooks VB (1986) The Neural Basis of Motor Control. New York: Oxford University Press.

CALFORD MB, TwEEDALE R (1990) Interhemispheric transfer of plasticity in the cerebral cortex. Science, 249, 805-807.

Cameron OG, Modell JG, Hihwa RD, Agranoff BW, Koeppe RA (1990) Changes in sensory-cognitive input: effects on cerebral blood flow. Journal of Cerebral Blood Flow and Metabolism, 10, 38-42.

CHAN J-L, Ross ED (1988) Left-handed mirror writing following right anterior cerebral artery infarction: evidence for nonmirror transformation of motor programs by right supplementary motor area. Neurology, Cleveland, 38, 59-63.

Chollet F, DiPiero V, Wise RJS, Brooks DJ, Dolan RJ, Frackowiak RSJ (1991) The functional anatomy of motor recovery after stroke in humans: a study with positron emission tomography. Annals of Neurology, 29, 63-71.

Colebatch JG, Findley LJ, Frackowiak RSJ, Marsden CD, Brooks DJ (1990) Preliminary report: activation of the cerebellum in essential tremor. Lancet, 336, 1028-1030.

Colebatch JG, Deiber M-P, Passingham RE, Friston KJ, Frackowiak RSJ (1991) Regional cerebral blood flow during voluntary arm and hand movements in human subjects. Journal of Neurophysiology, $65,1392-1401$.

Corbetta M, Miezin FM, Dobmeyer S, Shulman GL, Petersen SE (1990) Attentional modulation of neural processing of shape, color, and velocity in humans. Science, 248, 1556-1559.

Damasio AR (1985) Disorders of complex visual processing: agnosias, achromatopsia, Balint's syndrome, and related difficulties of orientation and construction. In: Principles of Behavioral Neurology. Edited by M.-M. Mesulam. Philadelphia: F. A. Davis, pp. 259-288.

DAmASIO AR, BENTON AL (1979) Impairment of hand movements under visual guidance. Neurology, New York, 29, 170-178.

DEECKE L (1987) Bereitschaftspotential as an indicator of movement preparation in supplementary motor area and motor cortex. In: Motor Areas of the Cerebral Cortex. Ciba Foundation Symposium 132. Edited by G. Bock, M. O'Connor and J. Marsh. Chichester: John Wiley, pp. 231-250.

Deiber M-P, Passingham RE, Colebatch JG, Friston KJ, Nixon PD, Frackowiak RSJ (1991) Cortical areas and the selection of movement: a study with positron emission tomography. Experimental Brain Research, 84, 393-402.

Denes G, CAviezel F, SemenzA C (1982) Difficulty in reaching objects and body parts: a sensorymotor disconnexion syndrome. Cortex, 18, 165-173.

DeYoe EA, VAN ESSEN DC (1988) Concurrent processing streams in monkey visual cortex. Trends in Neuroscience, 11, 219-226.

Economo C von (1929) The Cytoarchitectonics of the Human Cerebral Conex. London: Oxford University Press.

Ferro JM (1984) Transient inaccuracy in reaching caused by a posterior parietal lobe lesion. Journal of Neurology, Neurosurgery, and Psychiatry, 47, 1016-1019.

Ferro JM, Bravo-Marques JM, Castro-Caldas A, Antunes L (1983) Crossed optic ataxia: possible role of the dorsal splenium. Joumal of Neurology. Neurosurgery, and Psychiatry, 46, 533-539.

Fox PT, Mintun MA, Raich Le ME, Herscovitch P (1984) A noninvasive approach to quantitative functional brain mapping with $\mathrm{H}_{2}{ }^{15} \mathrm{O}$ and positron emission tomography. Joumal of Cerebral Blood Flow and Metabolism, 4, 329-333.

Fox PT, PerLmUtTer JS, Raichle ME (1985a) A stereotactic method of anatomical localization for positron emission tomography. Joumal of Computer Assisted Tomography, 9, 141-153. 
Fox PT, Raichle ME, Thach WT (1985b) Funtional mapping of the human cerebellum with positron emission tomography. Proceedings of the National Academy of Sciences of the USA, 82, 7462-7466.

Fox PT, Mintun MA, Reiman EM, Raichle ME (1988) Enhanced detection of focal brain responses using intersubject averaging and change-distribution analysis of subtracted PET images. Journal of Cerebral Blood Flow and Metabolism, 8, 642-653.

FreUNd HJ (1984) Premotor areas in man. Trends in Neurosciences, 7, 481-483.

Friston KJ, Frith CD, Liddle PF, Dolan RJ, Lammertsma AA, Frackowiak RSJ (1990) The relationship between global and local changes in PET scans. Joumal of Cerebral Blood Flow and Metabolism, 10, 458-466.

Fuster JM (1989) The Prefrontal Contex. Second edition. New York: Raven Press.

Garcin R, Rondot P, DE Recondo J (1967) Ataxie optique localisée aux deux hémichamps visuels homonymes gauches (étude clinique avec présentation d'une film). Revue Neurologique, 116, 707-714.

Gaymard B, Pierrot-Deseilligny C, Rivaud S (1990) Impairment of sequences of memory-guided saccades after supplementary motor area lesions. Annals of Neurology, 28, 622-626.

Ginsberg MD, Yoshil F, Vibulsresth S, Chang JY, Duara R, Barker WW et al. (1987) Human task-specific somatosensory activation. Neurology, Cleveland, 37, 1301-1308.

Godoy J, Lüders H, Dinner DS, Morris HH, Wyllie E (1990) Versive eye movements elicited by cortical stimulation of the human brain. Neurology, Cleveland, 40, 296-299.

GOLDBERG G (1985) Supplementary motor area structure and function: review and hypothesis. Behavioral and Brain Sciences, 8, 567-616.

Goldman-RAkic PS (1987) Motor control function of the prefrontal cortex. In: Motor Areas of the Cerebral Cortex. Ciba Foundation Symposium 132. Edited by G. Bock, M. O'Connor and J. Marsh. Chichester: John Wiley, pp. 187-200.

Grafton ST, Huang SC, Mahoney DK, Mazziotta JC, Phelps ME (1990) Analysis of optimal reconstruction filters for maximizing signal to noise ratios in PET cerebral blood flow subtraction studies. Joumal of Nuclear Medicine, 31, 865.

Grafton ST, Woods RP, Mazziotta JC, Phelps ME (1991) Somatotopic mapping of the primary motor cortex in humans: activation studies with cerebral blood flow and positron emission tomography. Joumal of Neurophysiology, 66, 735-743.

HAAXMA R, KUYPERS H (1974) Role of occipito-frontal cortico-contical connections in visual guidance of relatively independent hand and finger movements in thesus monkeys. Brain Research, Amsterdam, $71,361-366$.

Halsband U, Freund H-J (1990) Premotor cortex and conditional motor learning in man. Brain, 113, $207-222$.

Heilman KM, Van Den Abell T (1980) Right hemisphere dominance for attention: the mechanism underlying hemispheric asymmetries of inattention (neglect). Neurology, New York, 30, 327-330.

Heilman KM, Rothi LG, Mack L, Feinberg T, Watson RT (1986) Apaxia after a superior parietal lesion. Cortex, 22, 141-150.

Herscovitch P, Markham J, Raichle ME (1983) Brain blood flow measured with intravenous $\mathrm{H}_{2}^{15} \mathrm{O}$. I. Theory and error analysis. Joumal of Nuclear Medicine, 24, 782-789.

Ingvar DH, Philipson L (1977) Distribution of cerebral blood flow in the dominant hemisphere during motor ideation and motor performance. Annals of Neurology, 2, 230-237.

INHOFF AW, Diener HC, RAFAL RD, IVRY R (1989) The role of cerebellar structures in the execution of serial movements. Brain, 112, 565-581.

Jeannerod M, Prablanc C (1983) Visual control of reaching movements in man. Advances in Neurology, 39, 13-29.

Laplane D, Degos JD, Baulac M, Gray F (1981) Bilateral infarction of the anterior cingulate gyri and of the fornices. Journal of the Neurological Sciences, 51, 289-300.

Lassen na, Roland PE, Larsen B, Melamed E, SoH K (1977) Mapping of human cerebral functions: a study of the regional cerebral blood flow pattern during rest, its reproducibility and the activations seen during basic sensory and motor functions. Acta Neurologica Scandinavica, 56, Supplement 64, $262-263$.

Lauritzen M, Henriksen L, Lassen NA (1981) Regional cerebral blood flow during rest and skilled hand movements by xenon- 133 inhalation and emission computerized tomography. Joumal of Cerebral Bload Flow and Metabolism, 1, 385-387. 
LEINER HC, LeINER AL, DOw RS (1987) Cerebro-cerebellar learning loops in apes and humans. Italian Journal of Neurological Sciences, 8, 425-436.

Levine DN, KaUfman KJ, MoHr JP (1978) Inaccurate reaching associated with a superior parietal lobe tumor. Neurology, New York, 28, 556-561.

LISBERGER SG (1988) The neural basis for learning of simple motor skills. Science, 242, 728-735.

Logothetis NK, SCHall JD (1989) Neuronal correlates of subjective visual perception. Science, 245, $761-763$.

Lueck CJ, Zeki S, Friston KJ, Deiber M-P, Cope P, Cunningham VJ et al. (1989) The colour centre in the cerebral cortex of man. Nature, London, 340, 386-389.

LUNDBERG A (1971) Function of the ventral spinocerebellar tract: a new hypothesis. Experimental Brain Research, 12, 317-330.

Maunsell JHR, VAN Essen DC (1983) The connections of the middle temporal visual area (MT) and their relationship to a cortical hierarchy in the macaque monkey. Journal of Neuroscience, 3 , $2563-2586$.

Mazziotta JC, Huang S-C, Phelps ME, Carson RE, MacDonald NS, Mahoney K (I985a) A noninvasive positron computed tomography technique using oxygen-15-labeled water for the evaluation of neurobehavioral task batteries. Joumal of Cerebral Blood Flow and Metabolism, 5, $70-78$.

Mazziotta JC, Phelps ME, Wapenski JA (1985b) Human cerebral motor system metabolic responses in health and disease. Joumal of Cerebral Blood Flow and Metabolism, 5, Supplement 1, S213-S214.

Mesulam M-M (1981) A cortical network for directed attention and unilateral neglect. Annals of Neurology, $10,309-325$.

Mesulam M-M (1990) Large-scale neurocognitive networks and distributed processing for attention, language, and memory. Annals of Neurology, 28, 597-613.

Miezin FM, Fox PT, Raichle ME, Allman JM (1987) Localized responses to low contrast moving random dot patterns in human visual cortex monitored with positron emission tomography. Society for Neuroscience Abstracts, 13, 631 .

Miezin F, Applegate C, Petersen S, Fox P (1988) Brain regions in humans activated during smooth pursuit visual tracking. Society for Neuroscience Abstracts, 14, 795.

Mintun MA, RAichle ME, QuARLEs RP (1989) Length of PET data acquisition inversely affects ability to detect focal areas of brain activation. Joumal of Cerebral Blood Flow and Metabolism, 9, Supplement 1, S349.

MorRow MJ, SharPe JA (1990) Cerebral hemispheric localization of smooth pursuit asymmetry. Neurology, Cleveland, 40, 284-292.

Mountcastle VB, Lynch JC, Georgopoulos A, Sakata H, Acuna C (1975) Posterior parietal association cortex of the monkey: command functions for operations within extrapersonal space. Journal of Neurophysiology, 38, 871-908.

ORGOGOZO JM, LARSEN B (1979) Activation of the supplementary motor area during voluntary movement in man suggests it works as a supramotor area. Science, 206, 847-850.

Pearlanan AL, Birch J, Meadows JC (1979) Cerebral color blindness: an acquired defect in hue discrimination. Annals of Neurology, 5, 253-261.

Pelizzari CA, Chen GT, Spelbring DR, Weichselbaum RR, Chen C-T (1989) Accurate threedimensional registration of CT, PET, and/or MR images of the brain. Journal of Computer Assisted Tomography, 13, 20-26.

Penfield W, Boldrey E (1937) Somatic motor and sensory representation in the cerebral cortex of man as studied by electrical stimulation. Brain, 55, $389-443$.

Perenin M-T, Vighetto A (1988) Optic ataxia: a specific disruption in visuomotor mechanisms. Brain, $111,643-674$.

Pierrot-Deseillugny C, Gray F, Brunet P (1986) Infarcts of both inferior parietal lobules with impairment of visually gudied eye movements, peripheral visual inattention and optic ataxia. Brain, $109,81-97$.

Posner Mi, Petersen SE, Fox PT, Raichle ME (1988) Localization of cognitive operations in the human brain. Science, 240, 1627-1631.

RACZKOWSKI D, KALAT JW (1974) Reliability and validity of some handedness questionnaire items. Neuropsychologia, 12, 43-47. 
Raichle me, Martin WrW, Herscovitch P, Mintun Ma, Markham J (1983) Brain blood flow measured with intravenous $\mathrm{H}_{2}{ }^{15} \mathrm{O}$. II Implementation and validation. Joumal of Nuclear Medicine, $24,790-798$.

Ratio O, HuAng HK (1989) Calipso: an interactive software package for multimodality medical image analysis on a personal computer. Journal of Medical Imaging, 3, 205-216.

Roland PE (1984) Organization of motor control by the normal human brain. Human Neurobiology, 2, $205-216$.

Roland PE, Larsen B, Lassen NA, Skinhøj E (1980) Supplementary motor area and other cortical areas in organization of voluntary movements in man. Journal of Neurophysiology, 43, 118-136.

Roland PE, Meyer E, Shibasaki T, Yamamoto YL, Thompson CJ (1982) Regional cerebral blood flow changes in cortex and basal ganglia during voluntary movements in normal human volunteers. Journal of Neurophysiology, 48, 467-480.

RoNDOT P, DE RECONDO J (1974) Ataxie optique: trouble de la coordination visuo-motrice. Brain Research Amsterdam, 71, 367-375.

Rondot P, de Recondo J, Ribadeau Dumas JL (1977) Visuomotor ataxia. Brain, 100, 355-376.

Spitzer H, Desimone R, Moran J (1988) Increased attention enhances both behavioral and neuronal performance. Science, 240, 338-340.

STEIN JF (1986) Role of the cerebellum in the visual guidance of movement. Nature, London, 323, 217-221.

STRICK PL (1983) The influence of motor preparation on the response of cerebellar neurons to limb displacements. Journal of Neuroscience, 3, 2007-2020.

ТнАсн WT (1968) Discharge of Purkinje and cerebellar nuclear neurons during rapidly alternating arm movements in the monkey. Journal of Neurophysiology, 31, 785-797.

ТнАСн WT (1978) Correlation of neural discharge with pattern and force of muscular activity, joint position, and direction of intended next movement in motor cortex and cerebellum. Joumal of Neurophysiology, 41, $654-676$.

Trillet M, Croisile B, Laurent B (1989) L'agraphie pure: à propos de deux cas. Revue Neurologique, $145,720-724$.

Tsukahara N, Korn H, Stone J (1968) Pontine relay from cerebral cortex to cerebellar cortex and nucleus interpositus. Brain Research, Amsterdam, 10, 448-453.

Tzavaras A, Masure MC (1976) Aspects différents de l'ataxie optique selon la latéralisation hémisphérique de la lésion. Lyon Médical, 236, 673-683.

UNGERLEIDER LG, Desimone R (1986) Cortical connections of visual area MT in the macaque. Joumal of Comparative Neurology, 248, 190-222.

VACHANANDA B (1959) The major spinal afferent systems to the cerebellum and the cerebellar corticonuclear connections in Macaca mulatta. Joumal of Comparative Neurology, 112, 303-35I.

YIN TCT, MOUNTCASTLE VB (1977) Visual input to the visuomotor mechanisms of the monkey's parietal lobe. Science, 197, 1381-1383.

ZeK1 S (1980) The representation of colours in the cerebral cortex. Nature, London, 284, 412-418.

Zeki S, Watson JdG, Lueck CJ, Friston KJ, Kennard C, Frackowiak RSJ (1991) A direct demonstration of functional specialization in human visual cortex. Joumal of Neuroscience, 11, $641-649$.

(Received July 8, 1991. Revised November 18, 1991. Accepted December 11, 199I) 